\title{
Geoquímica das rochas meta-vulcânicas máficas do greenstone belt de Riacho de Santana, Bahia, Brasil
}

\author{
Angela Beatriz de Menezes Leal', Debajyoti Paul', Walter Peixoto da Silveira ${ }^{3}$, \\ Luiz Rogério Bastos Leal ${ }^{1}$, Simone Cerqueira Pereira Cruz ${ }^{1} \&$ Joilma Prazeres Santos ${ }^{4}$
}

\begin{abstract}
Resumo O greenstone belt de Riacho de Santana (GBRS), de idade arqueana, localizado no sudoeste do Estado da Bahia, Brasil, ocorre como unidade no embasamento cristalino do Bloco Gavião. Três unidades litoestratigráficas são reconhecidas no GBRS: (i) Unidade Inferior, compreende rochas ultramáficas komatíticas com finas intercalações de meta-basaltos e meta-gabros com quartzitos, meta-cherts, rochas cálcio-silicáticas e xistos aluminosos associados; (ii) Unidade Intermediária, constituída por meta-basaltos e meta-gabros, meta-tufos de composição intermediária a ácida, xistos alumonosos e xistos grafitosos, e (iii) Unidade Superior, compreende uma sequência de rochas silicáticas-carbonáticas. Neste trabalho, será apresentado a geoquímica de elementos maiores, traços e terras raras das rochas meta-vulcânicas máficas da Unidade Intermediária com inferências sobre os processos responsáveis pela formação destas rochas. Todas as amostras são classificadas como toleítos ricos em ferro. Padrões planos de ETRpesados e baixas razões entre ETRleves/ETRpesados nestas rochas é sugestivo de fusão relativamente rasa com ausência de granada na fonte. Padrões de ETR normalizados para o manto primitivo (e razões $\mathrm{Ba} / \mathrm{Zr}, \mathrm{Ba} / \mathrm{Nb}, \mathrm{Ti} / \mathrm{Y}, \mathrm{Nb} / \mathrm{Y}, \mathrm{Nb} / \mathrm{Th}$ e $\mathrm{Zr} / \mathrm{Y}$ ) sugerem que o magma primário das rochas meta-vulcânicas máficas do GBRS foi derivado a partir de reservatórios mantélicos enriquecidos ou por uma mistura entre reservatórios enriquecidos e empobrecidos. A composição do magma pode ter sido significantemente afetada por assimilação de material crustal de composição granítica, presença de sedimentos crustais subductados e/ou litofesfera subcontinetal Arqueana relativamente fina. Trabalhos futuros de isótopos de $\mathrm{Sr}, \mathrm{Nd}$ e $\mathrm{Pb}$ serão úteis para confirmar o efeito da contaminação crustal nestas rochas.
\end{abstract}

Palavras-chave: Greenstone belt Arqueano, geoquímica, rochas meta-vulcânicas máficas.

\begin{abstract}
Petrology of the mafic meta-volcanic rocks from the Riacho de Santana greenstone belt, Bahia, Brazil. The Riacho de Santana greenstone belt (GBRS) of Archaean age, located in the southwestern of Bahia State, Brazil, occurs as an unit in the regional crystalline basement rocks known as Gavião Block unit. Three distinct lithostratigraphic units are identified in GBRS: $(i)$ Lower Unit, comprising of komatiitic ultramafic rocks with thin intercalations of metabasalts, metagabbros, quartzites and metacherts, calc-silicates and aluminous schists; (ii) Intermediate Unit, comprising of fine-grained metabasalts and meta gabbros, intermediate to acid meta tuffs, aluminous schists, graphite schists; and (iii) Upper Unit, comprising of carbonate-silicate sequence. In this study, we report major, trace and earth rare element composition of the basic metavolcanic rocks belonging to the Intermediate Unit, and infer the likely source (s) for these metavolcanics. All of the samples may be classified as high-iron tholeiites. Flat HREE patterns and smaller LREE/HREE fractionation in these rocks suggest that these melts were generated at a shallow depth in the absence of garnet in the source mineralogy. Primitive-mantle normalized REE patterns (and $\mathrm{Ba} / \mathrm{Zr}, \mathrm{Ba} / \mathrm{Nb}, \mathrm{Ti} / \mathrm{Y}, \mathrm{Nb} / \mathrm{Y}, \mathrm{Nb} / \mathrm{Th}$, and $\mathrm{Zr} / \mathrm{Y}$ ratios) suggest that the primary magmas of these metavolcanics were derived from an enriched mantle reservoir or a mixture of enriched and depleted mantle reservoir. The magma composition was significantly affected by either due to assimilation of granitic crustal material, or due to the presence of subducted crustal sediments and/or thin Archaean subcontinental lithosphere in the mantle source region. Future work on $\mathrm{Sr}, \mathrm{Pb}$, and $\mathrm{Nd}$ isotope systematics may reveal the effect of crustal assimilation.
\end{abstract}

Keywords: Archaean greenstone belt, geochemistry, mafic metavolcanic rocks.

INTRODUÇÃ̃O Greenstone belts de idades arqueanas $(\sim 2.7$ to $3.5 \mathrm{Ga})$ são produtos de múltiplos processos geológicos, tais como: tectonismo, magmatis- mo, sedimentação e metamorfismo que operaram sob diferentes escalas espaciais e temporais (Condie 1981; de Wit 1998; Polat et al. 1998; van Hranendonk 2004;

1 - Programa de Pós-Graduação em Geologia, Departamento de Geoquímica/Geologia e Geofísica Aplicada, Instituto de Geociências, Universidade Federal da Bahia, Salvador (BA), Brasil. Email: angelab@ufba.br

2 - Department of Earth and Environmental Science, The University of Texas at San Antonio, San Antonio (TX), USA.

Email: debajyoti.paul@utsa.edu

3 - Companhia Baiana de Pesquisa Mineral - CBPM, Salvador (BA), Brasil. Email: peixoto@cbpm.com.br

4 - Programa Iniciação Científica, Dep. Geoquímica, Instituto de Geociências, UFBa, Salvador (BA), Brasil. 
Condie 2005; Polat \& Kerrich 2006; Benn et al. 2006). Destacam-se entre os greenstone belts arqueanos mais conhecidos e estudados no mundo, os da Província Superior do Canadá, na América do Norte (e.g., Polat \& Kerrich 2001; Cousens et al. 2002), os da Africa (e.g., Parman et al. 2001, 2003; Chavagnac 2004), os do oeste da Austrália (e.g., Bateman et al. 2001; Beresford et al. 2002), os do Craton do Dharwar, na Índia (e.g., Manikyamba et al. 2004; Srivastava et al. 2004) e os do Escudo Báltico, na Europa (e.g., Puchtel et al. 1999).

Na Plataforma Sul-Americana, inúmeros greenstone belts arqueanos ( $\sim 2.9$ to $3.2 \mathrm{Ga}$ ) são reconhecidos no Cráton do São Francisco, Estado da Bahia, entre eles destacam-se os de Contendas-Mirantes (Marinho
1991, 1994), Umburanas (Cunha \& Fróes 1994; Bastos Leal et al. 2003; Menezes Leal et al. 2007), Riacho de Santana (Silveira \& Garrido 2000; Menezes Leal et al. 2006) e Mundo Novo (Peucat et al. 2002) e outros de idade paleoproterozóica, como o de Itapicuru (Silva 1983,1987, 1994).

O greenstone belt de Riacho de Santana (GBRS) está localizado na porção sudoeste do Estado da Bahia, Brasil (Fig. 1) e ocorre como unidade no embasamento arqueano granítico-gnáissico-migmatítico do Bloco Gavião. Estratigraficamente, o GBRS compreende três unidades litológicas (Silveira \& Garrido 2000) denominadas de Superior, Intermediária e Inferior.

Neste trabalho, será apresentado a geoquímica
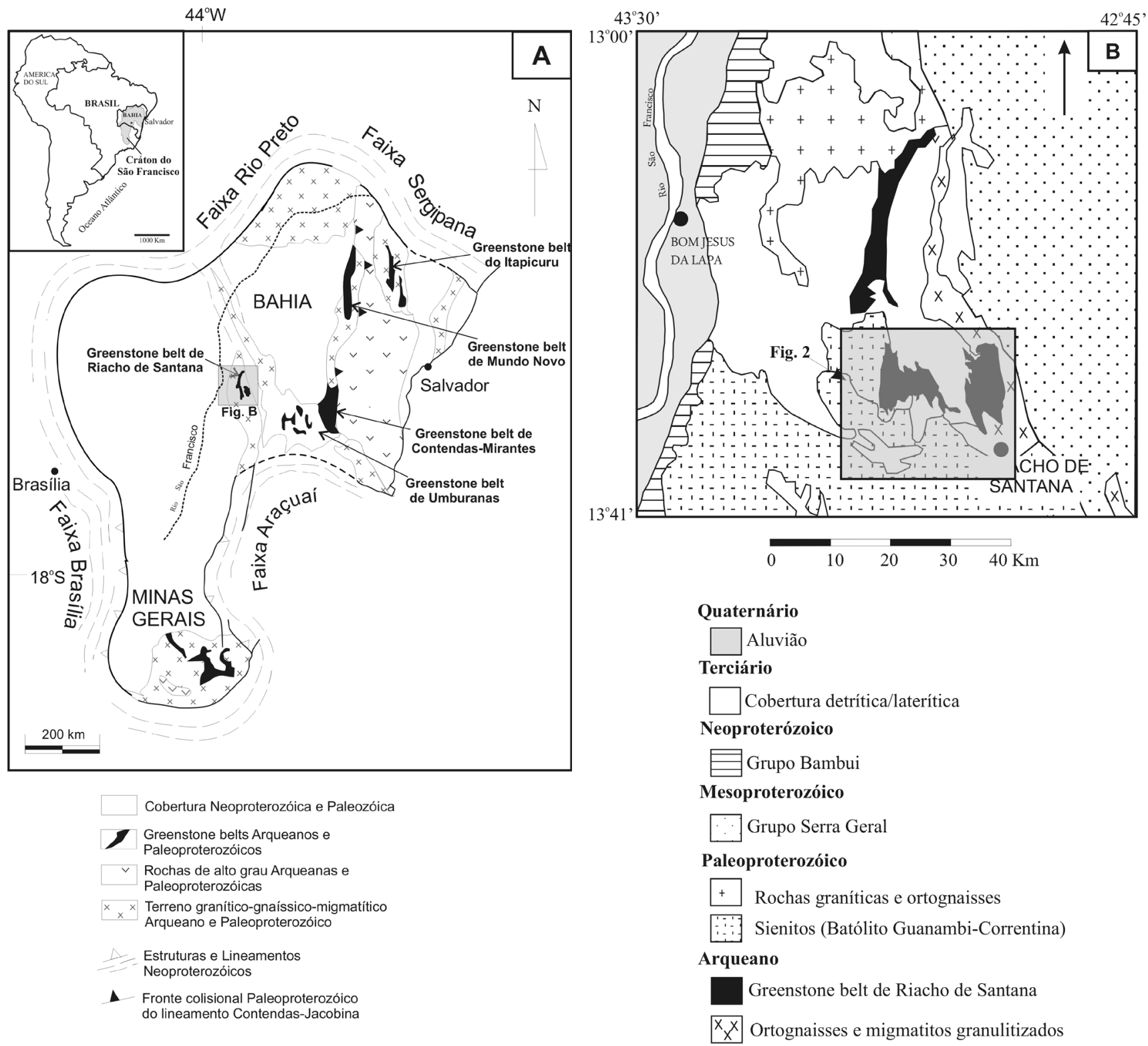

Figura 1 - Arcabouço geológico da porção centro-norte do Cráton do São Francisco. (A) Mapa geológico simplificado das principais unidades geológicas (Adaptado de Barbosa \& Sabaté 2002). (B) Mapa geológico regional do Greenstone belt de Riacho de Santana, Estado da Bahia, Brasil (Modificado e adaptado de Silveira \& Garrido 2000). 
de elementos maiores, traços e terras raras para as rochas meta-vulcânicas máficas da Unidade Intermediária do GBRS com inferências sobre a fonte mantélica e processos responsáveis pela formação destas rochas.

\section{GEOLOGIA DO GREENSTONE BELTS DE RIA-} CHO DE SANTANA (GBRS) O greenstone belt de Riacho de Santana (GBRS) está localizado na porção central do Cráton do São Francisco (CSF), a sudoeste do Estado da Bahia e dista cerca de $500 \mathrm{Km}$ da cidade de Salvador (Fig. 1A). O GBRS ocupa uma superfície de $\sim 1008 \mathrm{~km}^{2}$, com $84 \mathrm{~km}$ de comprimento e $12 \mathrm{~km}$ de largura média. O GBRS ocorre no embasamento arqueano (3.2 - 3.4 Ga) do Bloco Gavião (BG) (Barbosa \& Dominguez 1996; Bastos Leal 1998), o qual é constituído por terrenos granítico-gnáissico com variáveis graus de migmatização, formado por tonalitos-trodhjemitos, granodioritos e granitos (suítes TTG) e metamorfisados na fácies anfibolito. Rochas sieníticas e granitóides de idade paleoproterozóica $(\sim 2.0 \mathrm{Ga})$ são intrusivas no GBRS. O mapa geológico detalhado das unidades pertencentes ao GBRS é apresentado na figura 2.

O GBRS é dividido em três unidades litoestratigráficas (Silveira et al. 1996; Silveira \& Garrido 2000) (Fig. 2): (i) Unidade Inferior, compreende rochas ultramáficas komatiíticas com finas intercalações de metabasaltos e meta-gabros, associados a formações ferríferas bandadas (BIFs), quartzitos, meta-cherts, rochas cálcio-silicáticas e xistos aluminosos; (ii) Unidade Intermediária, constituída de meta-basaltos e meta-gabros, meta-tufos de composição intermediária a ácida, xistos aluminosos, xistos grafitosos e meta-cherts; e (iii) Unidade Superior constituída de uma seqüência de quartzitos e meta-carbonatos com meta-basaltos e meta-tufos asso-

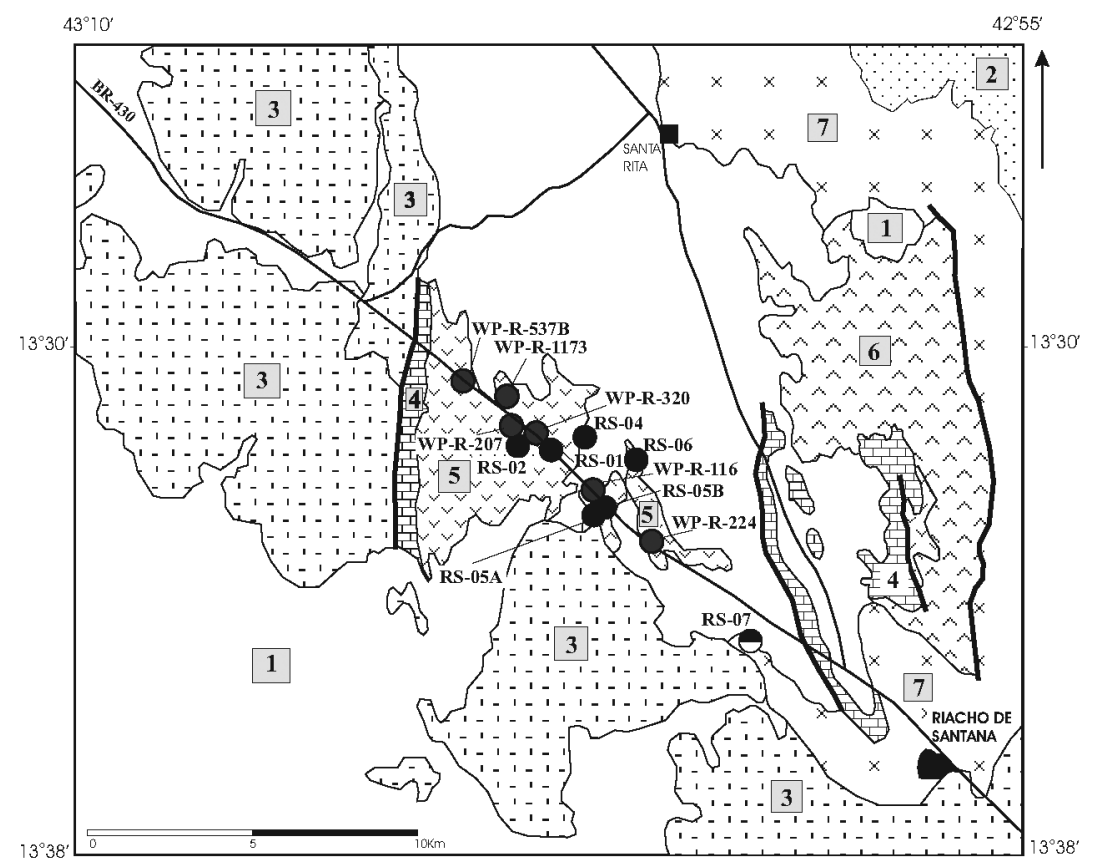

Figura 2 - Mapa geológico local (Modificado de Silveira \& Garrido 2000) do Greenstone belt de Riacho de Santana, Estado da Bahia, mostrando a distribuição das principais unidades. Cenozóico: 1. Aluvião e coberturas sedimentares detríticas. Mesoproterozóico (Grupo Serra Geral): 2. Quartzitos, filitos, xistos e conglomerados. Paleoproterozóico: 3. Álcali-sienitos e granitóides (Batólito Guanambi-Correntina). Arqueano: Greenstone belt Riacho de Santana. Unidade Superior: 4. Carbonatos e rochas cálcio-silicáticas com meta-cherts e formações ferriferas bandadas. Unidade Intermediária: 5. Meta-basaltos e meta-gabros, meta-cherts, meta-tufos e xistos em geral. Unidade Inferior: 6. Rochas ultramáficas komatiíticas com intercalações de meta-basaltos, meta-cherts, formações ferriferas bandadas e xistos em geral. Rochas do Embasamento: 7. Ortognaisses, migmatitos e ortognaisses granulitizados. A localização das amostras das rochas meta-vulcânicas máficas (círculos fechados) e uma amostra do embasamento (círculo metade preenchido) são mostradas no mapa. 
ciados, além de sericita e clorita xistos. Possui melhores exposições de afloramento na porção norte e noroeste da cidade de Riacho de Santana, apesar de apresentar comumente espessas coberturas de solo (Fig. 1B).

Dados isotópicos $\mathrm{Sm}-\mathrm{Nd}$ (dados não publicados de Bastos Leal) indicam uma idade isocrônica rocha total de $3.2 \pm 102 \mathrm{Ga}\left[\varepsilon_{\mathrm{Nd}}(\tau)=+2.3\right.$ to +3.7$]$ para as rochas meta-vulcânicas máficas da Unidade Inferior do GBRS.

Na porção leste do GBRS as rochas foram reequilibradas na fácies xisto verde gradando para a fácies anfibolito próximo do embasamento cristalino. As rochas do GBRS sofreram deformação progressiva em duas fases de dobramento coaxial (Silveira \& Garrido 2000).

AMOSTRAGEMETÉCNICASANALÍTICAS Um total de 12 (doze) amostras das rochas meta-vulcânicas máficas da Unidade Intermediária do GBRS foram selecionadas para a realização de análises químicas para os elementos maiores e traços. Em seis destas amostras foram dosados elementos terras raras. Foi analisada ainda uma amostra do embasamento gnáissico-migmatítico (RS-07) para efeito de comparação. As análises químicas foram efetuadas no Acme Analytical Laboratories, Vancouver, Canada. Os elementos maiores $\left(\mathrm{SiO}_{2}, \mathrm{Al}_{2} \mathrm{O}_{3}\right.$, $\mathrm{Fe}_{2} \mathrm{O}_{3}, \mathrm{CaO}, \mathrm{MgO}, \mathrm{Na}_{2} \mathrm{O}, \mathrm{K}_{2} \mathrm{O}, \mathrm{MnO}, \mathrm{TiO}_{2}, \mathrm{P}_{2} \mathrm{O}_{5}$, and $\mathrm{Cr}_{2} \mathrm{O}_{3}$ ) e alguns elementos traços (Ba, Nb, Ni, Sr, Sc, Y, and $\mathrm{Zr}$ ) foram dosados por Espectrômetro de Emissão ICP (Jarrel Ash AtomComp Model 975 /Spectro Ciros Vision) e os outros elementos traços e terras raras por Espectrômetro de Plasma Induzido (ICP-MS: PerkinElmer ELAN 6000). Perda ao fogo (LOI) foi estimada pela ignição em $1 \mathrm{~g}$ de amostra a $950^{\circ} \mathrm{C}$ por 90 minutos. A reprodutibilidade analítica $(1 \sigma)$ obtida através de 20 medidas repetidas do padrão SO-18) foi menor que 0.1 $\%$ para todos os elementos maiores, exceto para $\mathrm{SiO}_{2}(1 \sigma$ $=0.3 \%)$ e $\mathrm{Al}_{2} \mathrm{O}_{3}(1 \sigma=0.16 \%)$ e de $0.45 \%$ a $6.89 \%$ para elementos traços, exceto para $\mathrm{Ta}$, o qual teve um erro mais alto de $17.8 \%$.

\section{RESULTADOS}

Petrografia As rochas meta-vulcânicas máficas da Unidade Intermediária do GBRS apresentam granulação fina e coloração variando de cinza a verde. São isotrópicas a foliadas e, não raramente mostram presença de veios preenchidos por quartzo e epídoto.

O estudo microscópico revelou que a mineralogia primária é raramente preservada nestas rochas. Entretanto, as texturas ofítica e integranular são comuns e facilmente reconhecidas. As rochas meta-vulcânicas máficas são constituídas de hornblenda, tremolita/actinolita, plagioclásio, epídoto, esfeno, clorita e minerais opacos (óxidos de $\mathrm{Fe}$ e Ti). O plagioclásio apresenta composição albita e apresenta frequentemente sericitizado. É comum a presença de carbonato secundário, quartzo e epídoto preenchendo pequenas vênulas e fraturas, bem como disseminados na matriz. Em todas as amostras, a parâgenese mineral metamórfica observada é característica da fácies xisto verde. Presença de anfibólio (hornblenda) nas bordas dos raros cristais de piroxênio (onde a textura ígnea é preservada).
Geoquímica Através do estudo petrográfico sistemático foram selecionadas, para este trabalho, amostras menos alteradas para determinação de análise química de elementos maiores, traços e terras raras. No entanto, a presença de feldspato sericitizado, fraturas e vênulas preenchidas por epídoto e presença de carbonato secundário nas amostras estudadas sugerem que estas rochas possam ter sofrido alteração química durante o metamorfismo de baixo a médio grau. Como será mostrada, a dispersão de alguns elementos foi observada, principalmente nos diagramas entre elementos maiores e elementos LIL. Entretanto, os elementos HFS mostraram boa covariância. Inúmeros estudos geoquímicos (Humphris \& Thompson 1978; Kerrich \& Fyer 1979; Ludden et al. 1982; Murphy \& Hynes 1986; Arndt 1994; Brewer \& Menuge 1998) em rochas vulcânicas máficas e ultramáficas precambrianas sugeriram que os elementos HFS, elementos terras raras (ETR) (exceto Ce e Eu que são móveis), Y (comporta-se de foram semelhante aos ETR pesados), V, Al, Ti e Sc são menos susceptíveis a alteração durante o metamorfismo de fácies xisto verde. Em particular, razões entre elementos terras raras e entre os elementos HFS (e.g., $\mathrm{Zr} / \mathrm{Nb}$ e $\mathrm{Nb} / \mathrm{Th}$ ) em rochas vulcânicas de greenstone belts podem ser menos afetadas durante processos de alteração secundária pós-magmática (Condie 1994). Desta forma, razões de ETR e HFSE podem ser úteis na caracterização da composição mantélica das rochas meta-vulcânicas máficas do GBRS.

GEOQUIMICA DE ELEMENTOS MAIORES E TRAÇOS As composições dos elementos maiores, traços e terras raras são apresentadas na tabela 1. Os elementos maiores foram recalculados para $100 \%$, em base anidra, e utilizados nas figuras subseqüentes. Na figura $3 \mathrm{a}$ as rochas metavulcânicas plotam no campo dos basaltos toleíticos. No diagrama catiônico de Jensen (1976) todas as amostras plotam no campo dos toleítos ricos em ferro (HFT) (Fig. 3b).

Diagramas binários de variação utilizando como índice de evolução o $\mathrm{MgO}$ são mostrados na figura 4. Observa-se grande dispersão entre os elementos maiores, devido às alterações pós- magmáticas, conforme nos diagramas MPR (molecular proportion ration, Beswick \& Soucie 1978, Beswick 1982) e não mostrado neste trabalho. No geral, $\mathrm{o} \mathrm{Al}_{2} \mathrm{O}_{3}(12.26-14.90 \%)$ e $\mathrm{CaO}(6.42-12.32 \%)$ diminuem com o decréscimo de $\mathrm{MgO}$ (4.52 - $8.0 \%$ ) (com o fracionamento magmático), $\mathrm{SiO}_{2}(46.54-54.30 \%), \mathrm{TiO}_{2}(0.64-2.32 \%), \mathrm{FeO}_{\text {t }}$ $(11.09-18.51 \%)$ e $\mathrm{P}_{2} \mathrm{O}_{5}(0.07-0.41)$ aumentam seus teores com o decréscimo de $\mathrm{MgO}$. O trend mostrado pela variação de $\mathrm{Al}_{2} \mathrm{O}_{3}-\mathrm{MgO}$ sugere a importância do fracionamento de plagioclásio e clinopriroxênio no processo evolutivo. A correlação negativa entre $\mathrm{P}_{2} \mathrm{O}_{5} \mathrm{e}$ $\mathrm{MgO}$ sugere que a apatita pode ter sido concentrada nas fases iniciais da diferenciação magmática. $\mathrm{K}_{2} \mathrm{O}$ e $\mathrm{Na}_{2} \mathrm{O}$ mostram grande dispersão em suas concentrações indicando que estes elementos devem ter sido afetados durante o processo de metamorfismo regional. O comportamento entre $\mathrm{Sc}$ (verificado apenas para as amostra RS, Tab. 1) que diminui seus teores com o decréscimo 
Tabela 1 - Análises químicas de elementos maiores (\% em peso), traços (em ppm) e terras raras (em ppm) das rochas meta-vulcânicas máficas da Unidade Intermediária do greenstone belt de Riacho de Santana. A amostra RS-07 representa uma amostra do embasamento granítico-gnáissico do Bloco Gavião. WP-R amostras coletadas por Walter Peixoto, RS amostras coletadas por Angela Leal.

\begin{tabular}{|c|c|c|c|c|c|c|c|c|c|c|c|c|c|c|}
\hline Amostra & RS-01 & RS-02 & RS-04 & $\begin{array}{l}\text { RS- } \\
05 \mathrm{~A}\end{array}$ & $\begin{array}{l}\text { RS- } \\
\text { 05B }\end{array}$ & RS-06 & RS-07 & $\begin{array}{l}\text { WP- } \\
\text { R- } \\
537 \mathrm{~B}\end{array}$ & $\begin{array}{l}\text { WP- } \\
\text { R-116 }\end{array}$ & $\begin{array}{l}\text { WP- } \\
\text { R-207 }\end{array}$ & $\begin{array}{c}\text { WP- } \\
\text { R-224 }\end{array}$ & $\begin{array}{l}\text { WP- } \\
\text { R-320 }\end{array}$ & $\begin{array}{c}\text { WP- } \\
\text { R- } \\
1173\end{array}$ & $\begin{array}{c}\text { Precisão } \\
1 \sigma(\%)\end{array}$ \\
\hline $\mathrm{SiO}_{2}$ & 51.37 & 48.11 & 47.59 & 49.77 & 48.05 & 46.54 & 74.09 & 52.20 & 51.20 & 51.60 & 50 & 50.60 & 54.30 & 0.3 \\
\hline $\mathrm{TiO}_{2}$ & 1.07 & 1.04 & 2.32 & 0.96 & 1.07 & 2.38 & 0.16 & 0.64 & 1 & 0.87 & 1 & 1.30 & 0.98 & 0.01 \\
\hline $\mathrm{Al}_{2} \mathrm{O}_{3}$ & 14.49 & 13.38 & 12.26 & 14.55 & 14.78 & 14.44 & 13.90 & 13.40 & 14.10 & 14,90 & 14.50 & 14.90 & 13.70 & 0.16 \\
\hline $\mathrm{Fe}_{2} \mathrm{O}_{3}$ & 13.21 & 15.59 & 18.51 & 13.78 & 14.73 & 12.72 & 1.64 & 12.65 & 14.12 & 13.75 & 14 & 13.98 & 11.09 & 0.08 \\
\hline $\mathrm{MnO}$ & 0.19 & 0.22 & 0.30 & 0.18 & 0.19 & 0.52 & 0.02 & 0.23 & 0.24 & 0.35 & 0.21 & 0.22 & 0.19 & 0.01 \\
\hline $\mathrm{MgO}$ & 4.52 & 6.56 & 5.08 & 7.01 & 7.03 & 7.53 & 0.21 & 7.30 & 7 & 8 & 7.20 & 6 & 6.30 & 0.03 \\
\hline $\mathrm{CaO}$ & 10.89 & 12.32 & 7.97 & 10.99 & 10.51 & 6.42 & 1.03 & 10.5 & 10.9 & 9.60 & 11.70 & 10 & 8,20 & 0.05 \\
\hline $\mathrm{Na}_{2} \mathrm{O}$ & 3.34 & 1.76 & 2.02 & 1.82 & 2.60 & 2.43 & 3.89 & 2.20 & 1.90 & 0.98 & 1.30 & 2.70 & 4.10 & 0.06 \\
\hline $\mathrm{K}_{2} \mathrm{O}$ & 0.23 & 0.31 & 0.18 & 0.18 & 0.16 & 0.40 & 4.61 & 0.27 & 0.21 & 0.06 & 0.16 & 0.27 & 0.08 & 0.5 \\
\hline $\mathrm{P}_{2} \mathrm{O}_{5}$ & 0.12 & 0.10 & 0.15 & 0.09 & 0.10 & 0.41 & 0.04 & 0.07 & 0.09 & 0.09 & 0.09 & 0.11 & 0.08 & 0.02 \\
\hline $\mathrm{CO}_{2}$ & 0.01 & 0.02 & 0.58 & 0.05 & 0.05 & 0.63 & 0.06 & 0.32 & 0.15 & 0.29 & 0.11 & 0.14 & 0.13 & - \\
\hline LOI & 0.50 & 0.60 & 2.80 & 0.60 & 0.70 & 6.10 & 0.40 & 0.84 & 0.70 & 0.58 & 0.51 & 0.49 & 0.77 & - \\
\hline TOTAL & 99.99 & 100.02 & 99.98 & 99.98 & 99.97 & 100.52 & 100.05 & 100.62 & 101.61 & 101.07 & 100.78 & 100.71 & 99.92 & - \\
\hline $\mathrm{Cr}$ & 37 & 20 & 10 & 31 & 33 & 12 & 10 & 170 & 265 & 198 & 141 & 245 & 92 & 0.01 \\
\hline $\mathrm{Ni}$ & 22.8 & 15.8 & 1.4 & 42.4 & 73.3 & 59.1 & 1.4 & 91 & 87 & 86 & 108 & 70 & 48 & 6.8 \\
\hline Co & 61.2 & 56.2 & 60.1 & 51.8 & 59.6 & 51.7 & 2.1 & - & - & - & - & - & - & 0.8 \\
\hline $\mathrm{Cu}$ & 103 & 14.1 & 35.8 & 120 & 166 & 43.3 & 1 & - & - & - & - & - & - & 7 \\
\hline $\mathrm{V}$ & 277 & 295 & 53 & 301 & 329 & 225 & 6 & - & - & - & - & - & - & 7 \\
\hline $\mathrm{Sc}$ & 37 & 38 & 52 & 35 & 39 & 31 & 2 & - & - & - & - & - & - & 0.75 \\
\hline Cs & 0.1 & 0.9 & 0.4 & 0.4 & 0.1 & 3.8 & 5.8 & - & - & - & - & - & - & 0.2 \\
\hline $\mathrm{Ba}$ & 45.2 & 53.6 & 41.3 & 40.5 & 67.2 & 208 & 969 & 14 & 48 & $<10$ & $<10$ & 48 & 16 & 4.6 \\
\hline $\mathrm{Rb}$ & 2 & 9.7 & 6.8 & 5.7 & 4 & 8.3 & 169 & 14 & 11 & 10 & 9 & 10 & 8 & 1 \\
\hline $\mathrm{Sr}$ & 138 & 123 & 117 & 105 & 80.9 & 152 & 180 & 104 & 87 & 90 & 111 & 124 & 91 & 4.2 \\
\hline $\mathrm{Nb}$ & 3.3 & 3 & 4 & 2.3 & 2.5 & 15.4 & 6.10 & 8 & $<5$ & $<5$ & $<5$ & $<5$ & 9 & 0.6 \\
\hline $\mathrm{Hf}$ & 2.3 & 1.9 & 2.4 & 2.1 & 1.8 & 4.9 & 3.3 & $<8$ & $<8$ & $<8$ & $<8$ & $<8$ & $<8$ & 0.4 \\
\hline $\mathrm{Zr}$ & 74.2 & 70.6 & 85.5 & 59 & 65 & 177 & 177 & 61 & 81 & 75 & 77 & 102 & 78 & 3.9 \\
\hline $\mathrm{Y}$ & 25.1 & 27.6 & 34.4 & 24.6 & 27.2 & 34.7 & 34.7 & 12 & 16 & 15 & 20 & 21 & 15 & 0.8 \\
\hline U & 0.4 & 0.4 & 0.2 & 0.2 & 0.2 & 0.4 & 0.4 & - & - & - & - & - & - & 0.4 \\
\hline Th & 1.8 & 0.9 & 1.2 & 1.2 & 0.6 & 1.3 & 1.3 & $<5$ & $<5$ & $<5$ & $<5$ & $<5$ & $<5$ & 0.7 \\
\hline $\mathrm{Ta}$ & 0.2 & 0.2 & 0.2 & 0.1 & 0.1 & 0.9 & 0.4 & - & - & - & - & - & - & 0.2 \\
\hline $\mathrm{Zn}$ & 19 & 14 & 36 & 12 & 15 & 279 & 21 & - & - & - & - & - & - & 7.8 \\
\hline $\mathrm{La}$ & 7.3 & 7.5 & 3 & 4.3 & 4.3 & 21.6 & 40.1 & - & - & - & - & - & - & 0.3 \\
\hline $\mathrm{Ce}$ & 15.3 & 15.2 & 7.8 & 10.1 & 10.7 & 45.5 & 65 & - & - & - & - & - & - & 0.7 \\
\hline $\operatorname{Pr}$ & 2.34 & 2.29 & 1.49 & 1.58 & 1.54 & 6.18 & 6.71 & - & - & - & - & - & - & 0.1 \\
\hline $\mathrm{Nd}$ & 12.9 & 9.9 & 8.5 & 7.8 & 10.2 & 24.4 & 23.3 & - & - & - & - & - & - & 0.5 \\
\hline $\mathrm{Sm}$ & 2.6 & 2.4 & 3 & 2.8 & 2.5 & 6.7 & 3 & - & - & - & - & - & - & 0.1 \\
\hline $\mathrm{Eu}$ & 1.09 & 1.03 & 1.40 & 0.96 & 0.94 & 1.57 & 0.49 & - & - & - & - & - & - & 0.03 \\
\hline $\mathrm{Gd}$ & 3.96 & 3.94 & 5.24 & 3.43 & 3.88 & 6.10 & 2.54 & - & - & - & - & - & - & 0.1 \\
\hline $\mathrm{Tb}$ & 0.67 & 0.63 & 0.91 & 0.66 & 0.65 & 1.01 & 0.37 & - & - & - & - & - & - & 0.03 \\
\hline Dy & 4.35 & 4.15 & 5.65 & 4.56 & 4.30 & 6.48 & 1.65 & - & - & - & - & - & - & 0.1 \\
\hline Ho & 0.96 & 1.01 & 1.30 & 0.90 & 1 & 1.38 & 0.24 & - & - & - & - & - & - & 0.03 \\
\hline Er & 2.84 & 2.45 & 3.80 & 2.65 & 2.79 & 3.85 & 0.67 & - & - & - & - & - & - & 0.1 \\
\hline $\mathrm{Tm}$ & 0.38 & 0.36 & 0.54 & 0.34 & 0.39 & 0.49 & 0.10 & - & - & - & - & - & - & 0.02 \\
\hline $\mathrm{Yb}$ & 2.15 & 2.52 & 3.16 & 2.73 & 2.39 & 3.03 & 0.43 & - & - & - & - & - & - & 0.1 \\
\hline $\mathrm{Lu}$ & 0.41 & 0.45 & 0.58 & 0.41 & 0.48 & 0.52 & 0.12 & - & - & - & - & - & - & 0.01 \\
\hline
\end{tabular}

Nota: A precisão de $1 \sigma$ é computada para 20 análises repetidas para o padrão SO-18. 

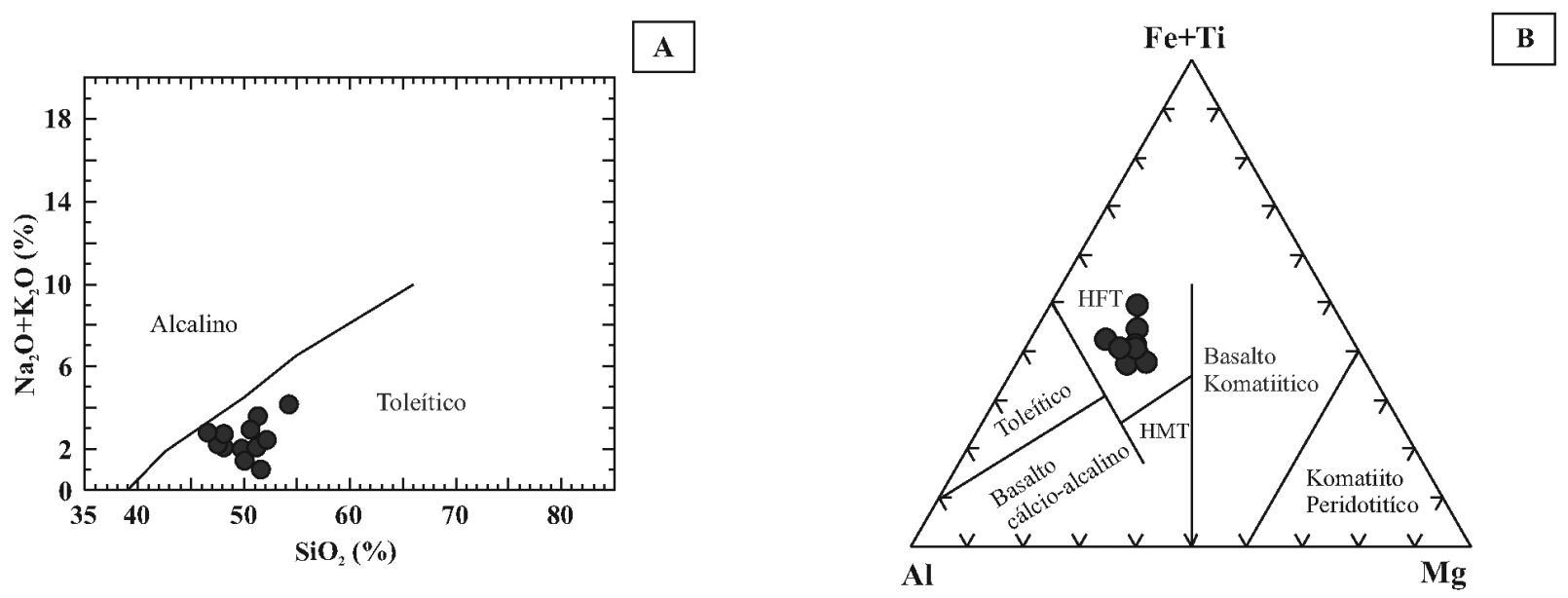

Figura 3 - (A) Diagrama sílica - álcalis (Na2O + K2O) para as rochas meta-vulcânicas máficas do GBRS segundo a classificação de Irvine \& Baragar (1971). (B) Diagrama catiônico de Jensen (1976). HTTToleitos ricos em ferro e HMT-Toleitos ricos em MgO. Círculos fechados representam as amostras metavulcânicas máficas do GBRS. Esta mesma simbologia é mantida para as figuras subsequentes.

de $\mathrm{CaO} / \mathrm{Al}_{2} \mathrm{O}_{3}$ ratificam o trend evolutivo do clinopiroxênio no fracionamento magmático.

Diagramas de variação entre elementos traços com o $\mathrm{MgO}$ são mostrados na figura 5. Observa-se uma grande dispersão dos trends entre as razões $\mathrm{Rb} / \mathrm{Sr}, \mathrm{Zr} /$ $\mathrm{Nb}$ e $\mathrm{La} / \mathrm{Sm}$ com a variação do $\mathrm{MgO}$ nas rochas metavulcânicas máficas do GBRS, refletindo alterações pósmagmáticas. Entretanto, Rb e Sr mostram, respectivamente, correlações positiva e negativa com a variação do $\mathrm{MgO}$. O teor de Ni diminui com o decréscimo de $\mathrm{MgO}$ (4.52-8.0 \%) e a $\sim 5 \%$ de $\mathrm{MgO}$ o conteúdo de $\mathrm{Ni}$ aproxima-se de zero (Fig. 5). Este comportamento elemental é sugestivo do fracionamento de olivina no processo evolutivo magmático.

Padrões de ETR normalizados para o manto primitivo (McDonough \& Sun, 1995) são apresentados na figura 6 . A figura 6 revela três padrões de ETR, semelhante aos spidergram (não mostrados neste trabalho): (i) uma amostra (RS-04) segue o padrão de ETR leves (trend positivo) definido pela média dos Basaltos de Cordilheira Meso-Oceânica Normal (N-MORB), entretanto, possui padrões de ETR intermediários e pesados mais elevados comparados com o N-MORB. Esta amostra possui também concentrações mais elevadas em elementos LIL comparada com o N-MORB e anomalias negativas de $\mathrm{Ba}$ e $\mathrm{Nb}$ e positiva de $\mathrm{K}$ semelhante ao padrão observado para o embasamento granítico-gnáissico do Bloco Gavião (amostra RS-07), podendo ser resultado da interação entre o magma e a litosfera continental. (ii) duas amostras (RS-05A e RS05B) mostram padrão de ETR aproximadamente plano (ETR leve e pesado), sugerindo uma derivação de uma fonte mantélica primitiva. (iii) duas amostras (RS-01 e RS-02) mostram padrão de ETR leves e pesados semelhante à média dos Basaltos de Cordilheira MesoOceânica enriquecido (E-MORB). (iv) uma amostra (RS-06) mostra padrão de ETR leves mais enriquecido semelhantes aos Basaltos de Ilha Oceânica (OIB), mas possuem comportamento dos ETR pesados planos.

Anomalia negativa de $\mathrm{Sr}$ é presente em todas as amostras e no embasamento do BG (amostra RS-07). A amostra RS-06 é caracterizada por apresentar anomalia negativa de Eu (Fig. 6) semelhante àquela observada na amostra do embasamento, e uma anomalia negativa de $\mathrm{K}$ similar àquelas observadas no N-MORB e OIB. Para as outras amostras, a ausência de anomalia negativa de Eu no diagramas da figura 6, indica que o fracionamento de plagioclásio não ocorreu. Entretanto, valores menores do fracionamento das razões entre ETR leves/ ETR pesados e padrão relativamente plano dos ETR pesados nas amostras são sugestivos que as fusões foram provavelmente geradas em profundidade rasa (no campo espinélio-lherzolito), na ausência de granada na mineralogia da fonte. Os padrões de ETR normalizados para o manto primitivo (e a abundância dos elementos traços) das rochas meta-vulcânicas máficas do GBRS são semelhantes àqueles observados de rochas metavulcânicas máficas de outros greenstone belts arqueanos (e.g., Abitibi (Escudo Canadense), Olondo (Escudo de Aldan) e Bastar (Índia Central)).

\section{DISCUSSÃO}

Assimilação Crustal? Alguns autores têm mencionado que plumas mantélicas (porções mais profundas do manto) podem ser contaminadas pela assimilação com a litosfera continental (e.g., Mahoney et al. 1983; Mohr 1987), pelo manto astenosférico com assinatura empobrecida ou por fusões de litosfera oceânica (e.g. Chen \& Frey 1983, 1985; Schilling et al. 1985). Estas hipóteses são frequentemente formuladas para explicar o enriquecimento anômalo de elementos LIL em basaltos continentais (Cox \& Hawkesworth 1985; Campbell 1985). Observa-se nas rochas meta-vulcânicas do GBRS significativas variações em elementos LIL. Embora estas variações possam refletir processos de alteração durante o metamorfismo de baixo grau, a presença de anomalia 

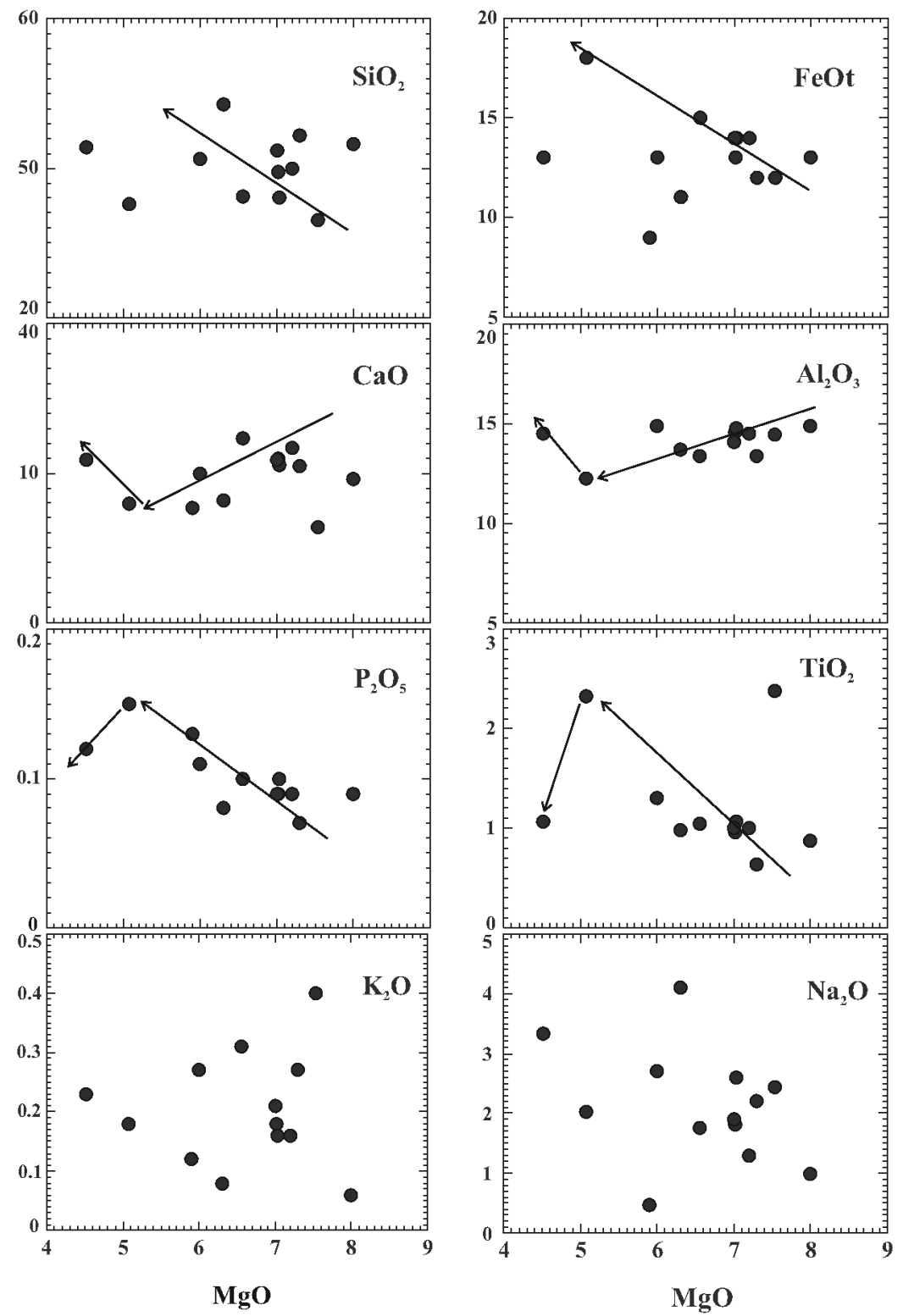

Figura 4 - Diagrama de variação entre $\mathrm{MgO}$ (\% em peso) e elementos maiores (\% em peso) para as rochas meta-vulcânicas máficas do GBRS.

negativa de $\mathrm{Sr}$, similar àquelas observadas do embasamento, sugere contaminação destes magmas com as rochas do embasamento granítico-gnáissico do $\mathrm{BG}$.

O processo de contaminação/assimilação crustal pode ser investigado utilizando razões entre elementos, como $\mathrm{Ti} / \mathrm{Y}, \mathrm{Ba} / \mathrm{Nb}$ e $\mathrm{Ba} / \mathrm{Zr}$, pois a crosta é enriquecida em elementos LIL (Rollinson 1993). Estas razões estão plotadas na figura 7. É observado nessa figura que cinco das amostras das rochas meta-vulcânicas máficas plotam ao longo de uma mistura curvilínea entre a média do N-MORB e rochas do embasamento. Tal comportamento pode resultar na mistura de $<5 \%$ das rochas do embasamento com fusões derivadas de uma fonte MORB. As outras amostras plotam entre NMORN e OIB. Estes resultados sugerem que as rochas meta-vulcânicas máficas do GBRS foram afetadas por algum grau de assimilação crustal. Entretanto, é difícil explicar o efeito da contaminação crustal somente com as observações detalhadas acima. Estudos futuros da composição isotópica do $\mathrm{Sr}$, $\mathrm{Nd}$ e $\mathrm{Pb}$ poderão confirmar a hipótese de contaminação crustal aventada para explicar o comportamento anômalo de alguns elementos químicos das rochas metavulcânicas do GBRS.

Investigação da Fonte Mantélica Utilizando Razões entre elementos HFS Inúmeros trabalhos (e.g., Weaver 1991; Fitton et al. 1997; Baksi 2001; Condie 2003, 2005) foram realizados utilizando razões entre elementos HFS, tais como $\mathrm{Nb} / \mathrm{Th}, \mathrm{Zr} / \mathrm{Nb}, \mathrm{Zr} / \mathrm{Y}$ e $\mathrm{Nb} / \mathrm{Y}$ para caracterizar domínios mantélicos isotopicamente distintos (e.g., Hart et al. 1992) em rochas vulcânicas máficas de greenstone belts. Como estes elementos são considerados altamente incompatíveis, suas razões no processo de fusão permanecem relativamente constantes e podem indicar hetero- 

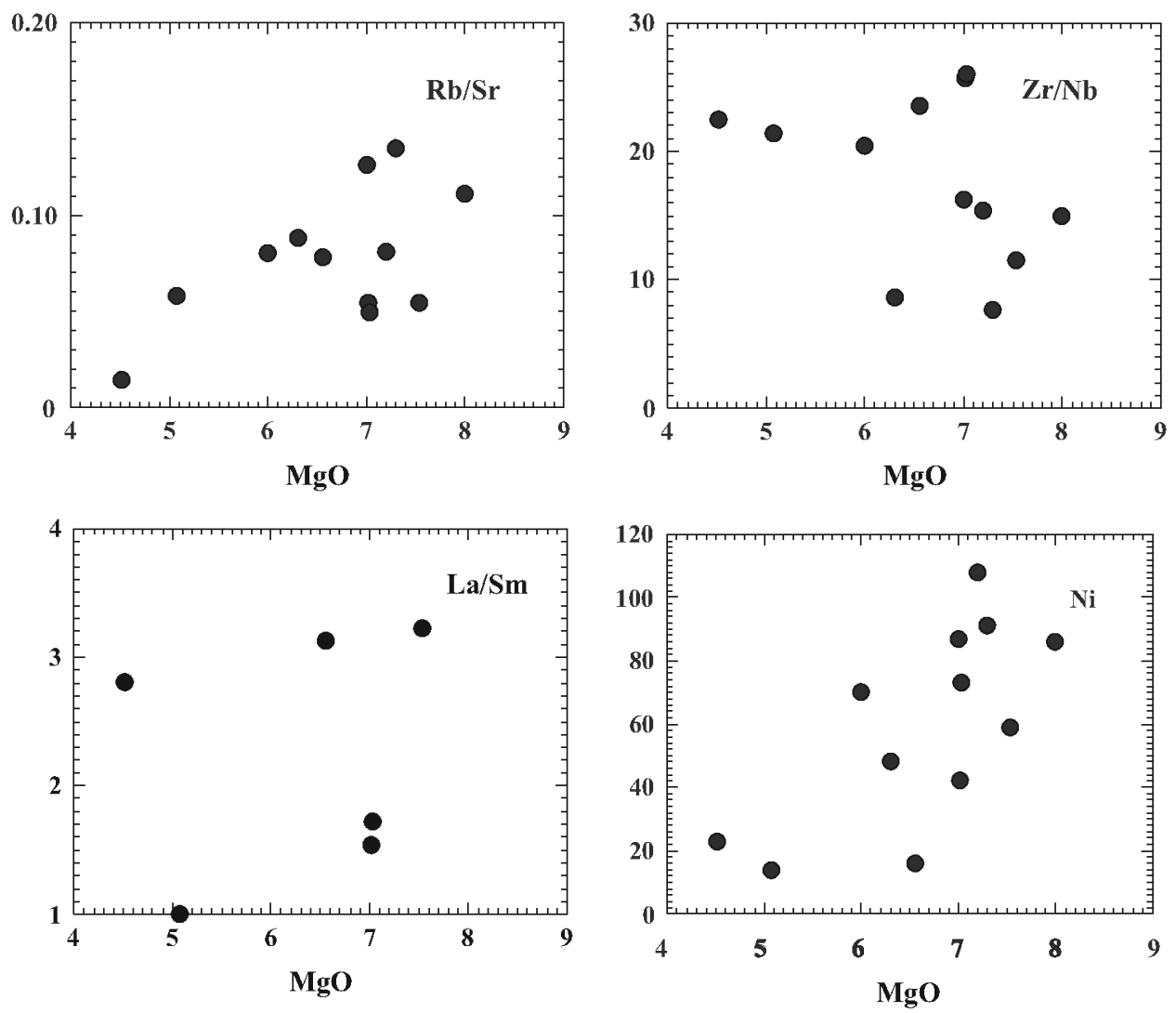

Figura 5 - Diagrama de variação entre $\mathrm{MgO}$ (\% em peso) e $\mathrm{Rb} / \mathrm{Sr}, \mathrm{Zr} / \mathrm{Nb}, \mathrm{La}$ / Sm e Ni (ppm) para as rochas meta-vulcânicas máficas do GBRS.

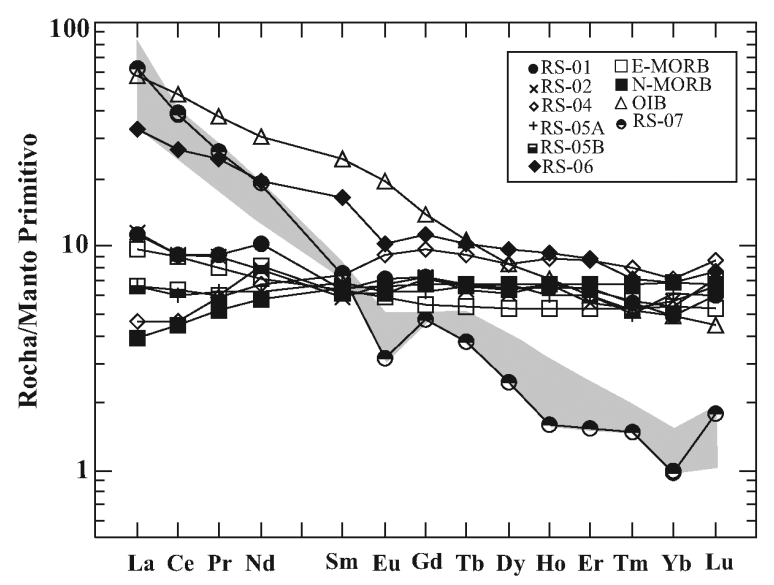

Figura 6 - Diagrama de elementos terras raras (ETR) normalizados para o manto primitivo (McDonough \& Sun 1995) para as rochas meta-vulcânicas máficas do GBRS. Para comparação são mostrados no diagrama os padrões médios para Basaltos de Ilha Oceânica (OIB) e Basaltos de Cordilheira MesoOceânica Normal (N-MORB) e Enriquecido (E-MORB) (Sun \& McDonough 1989). O campo em cinza representa uma média de rochas do embasamento granítico-gnáissico do Bloco Gavião (Dados químicos extraído de Bastos Leal et al. 1998). geneidade mantélica. No diagrama utilizando $\mathrm{Nb} / \mathrm{Y}$ vs. $\mathrm{Zr} / \mathrm{Y}$ (Fig. 8a), fontes derivadas de plumas são diferenciadas de fontes não-pluma (manto empobrecido e magmas de arco vulcânico). Na figura 8a, as amostras das rochas meta-vulcânicas máficas do GBRS plotam ao longo ou próximo da linha divisória entre fontes mantélica derivadas de pluma e não-pluma. As amostras podem ser divididas em dois grupos: o primeiro grupo com baixa razão $\mathrm{Zr} / \mathrm{Y}$ e Nb/Y, e o segundo com valores relativamente altos nas razões $\mathrm{Zr} / \mathrm{Y}$ e $\mathrm{Nb} / \mathrm{Y}$. O primeiro grupo plota próximo do campo do manto empobrecido (DM) e mostra indicação de mistura entre DM e manto empobrecido profundo (DEP). Uma amostra (RS-04) plota próxima de manto empobrecido em profundidades rasas (DM) e pode ser resultado da mistura de DM e manto primordial (PM). O segundo grupo pode ser resultante da mistura entre PM e fonte mantélica enriquecida (EM); poucas amostras deste grupo que plotam no campo de fonte pluma pode ter sido formada pela mistura entre EM e OIB. Dentro deste contexto, EM representaria porções do manto enriquecido pela adição de litosfera oceânica subductada e/ou litosfera subcontinental junto com sedimentos crustais. Por outro lado, o diagrama $\mathrm{Zr} / \mathrm{Nb}$ vs. $\mathrm{Nb} / \mathrm{Th}$ (Fig. 8b) revela que algumas amostras plotam próximo da média EM e crosta superior (UC), enquanto que apenas uma amostra plota no campo dos basaltos oceânicos. Embora nenhuma amostra demonstre evidências de ter sido derivada de apenas fonte do tipo DM, três amostras plotam entre 

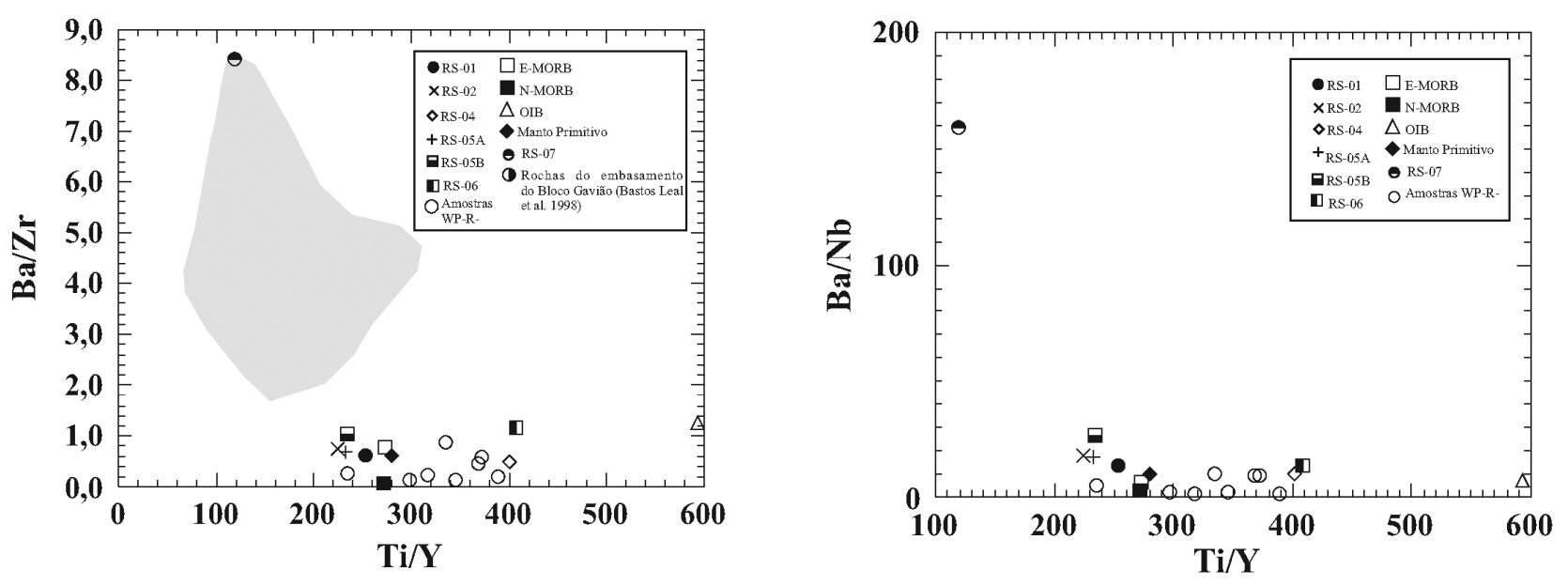

Figura 7 - Diagrama de variação Ti/Y vs. Ba/Zr e Ba/Nb para as rochas meta-vulcânicas máficas do GBRS. O campo em cinza representa uma média de rochas do embasamento granítico-gnáissico do Bloco Gavião (BG) extraído de Bastos Leal et al. (1998). Bastos Leal et al. (1998) não analisaram Ba e Nb nestas rochas. Valores para os componentes mantélicos (N-MORB, E-MORB e OIB) são de Sun \& McDonough (1989) e manto primitivo de McDonough \& Sun (1995).
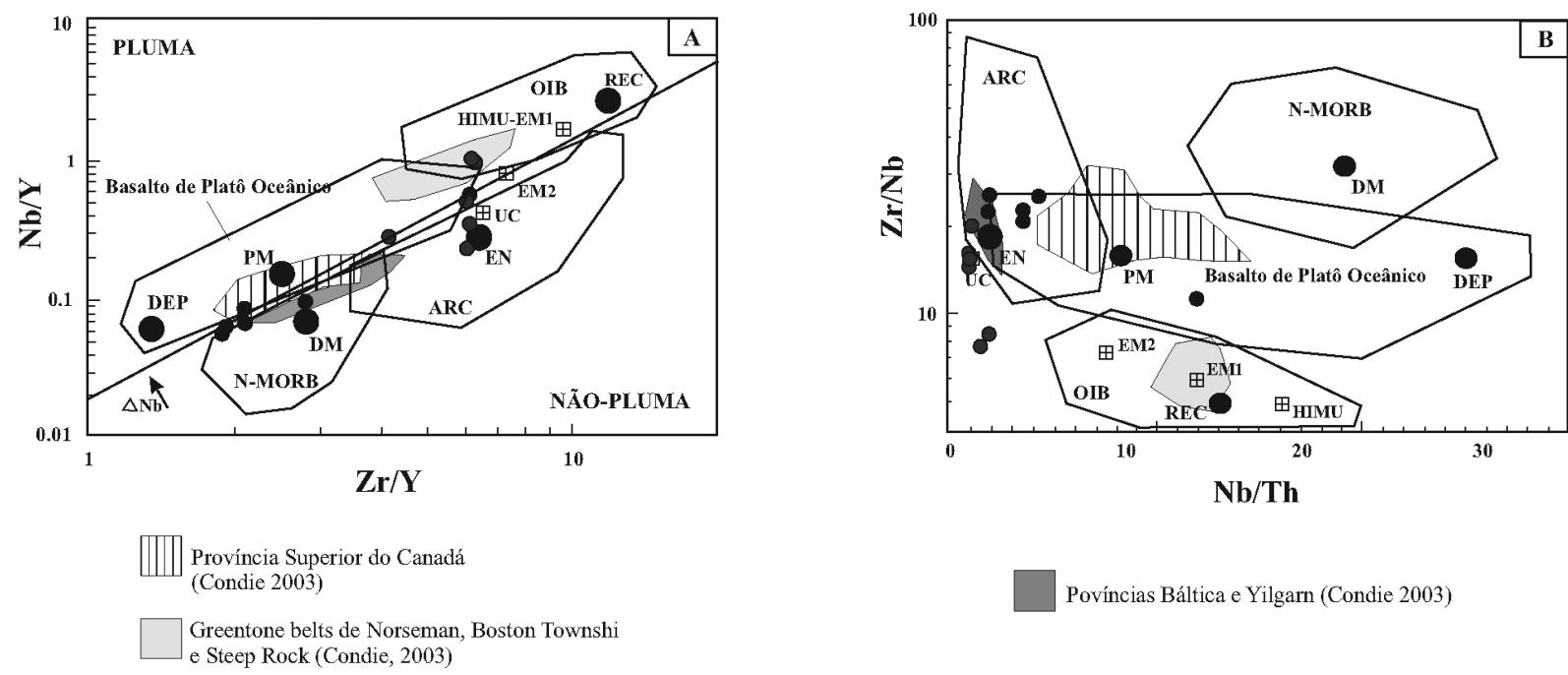

Figura 8 - Inferência da(s) fonte(s) das rochas meta-vulcânicas máficas do GBRS utilizando diagramas de variação (a) $\mathrm{Zr} / \mathrm{Y}$ vs. $\mathrm{Nb} / \mathrm{Y}$ e (b) $\mathrm{Nb} / \mathrm{Th}$ vs. $\mathrm{Zr} / \mathrm{Nb}$. Nestas figuras são mostrados campos de fontes mantélicas de basaltos associados a diversos ambientes tectônicos (Condie 2005). Abreviações: UC, crosta continental superior; PM, manto primitivo; DM, manto empobrecido raso; HIMU, alto $\mu U$ (fonte U/Pb); EM1 e EM2, fontes mantélicas enriquecidas; ARC, basaltos de arco; DEP, fonte mantélica empobrecida profunda; EN, componentes enriquecidos; REC, componentes reciclados. Dados de outros greenstone belts Arqueanos são mostrados para comparação: Província Superior do Canadá (campo tracejado), Províncias Báltica e Yilgarn (campo cinza escuro), greenstones Norseman, Boston Township e Steep Rock Late (campo cinza claro).

as fontes EM e DM, possuindo, no entanto, contribuição menos significativa de DM.

A razão $\mathrm{Rb} / \mathrm{Cs}$ pode ser utilizada para distinguir reservatórios $\mathrm{PM}(\mathrm{Rb} / \mathrm{Cs}=20)$ de reservatórios do tipo OIB $(\mathrm{Rb} / \mathrm{Cs}=80)($ Hofmann \& White 1983; McDonough et al. 1987). Embora os elementos Rb e Cs sejam levemente afetados durante os processos de alteração, algumas amostras das rochas metavulcânicas do GBRS possuem razão $\mathrm{Rb} / \mathrm{Cs}$ entre $10-20$ similar às razões observadas nos reservatórios do tipo PM, exceto para uma amostra que apresentou teor de 40 . A razão $\mathrm{Ce} / \mathrm{Pb}$ no OIB/MORB é 25 e no PM é 9 (McDonough et al. 1987). As amostras estudadas apresentaram razão Ce/ $\mathrm{Pb}$ variando entre 8 e 26 (três amostras variando 8-10 e 
três variando entre 17-26). A amostra RS-04 plota próximo do DM na figura 8a, possui razão $\mathrm{Th} / \mathrm{U}$ de $2.25 \mathrm{e}$ razão $\mathrm{La} / \mathrm{Sm}$ de 0.35 . Estes valores apresentados são típicos de manto empobrecido (Galer \& O'Nions 1985). Além disso, os dados apresentados sugerem a presença de manto do tipo empobrecido na região fonte.

Condie (2005) sugeriu que não existe manto geoquimicamente empobrecido em tempos Arqueano, devido à reciclagem e mistura com frações significativas de componentes enriquecidos. Entretanto, os dados apresentados do GBRS não descartam a possibilidade de basaltos derivados de fonte mantélica rasa e empobrecida ou a presença de componentes mantélicos depletados; alguns basaltos da Província Superior do Canadá foram provavelmente derivados de reservatórios mantélicos empobrecidos em profundidades relativamente rasas (Polat et al. 1999). Os dados químicos das rochas meta-vulcânicas máficas do GBRS mostram evidências de mistura entre componentes EM e DM (Fig. 8b). Da mesma forma, os padrões de ETR (Fig. 6) e os diagramas apresentados na figura 7 sugerem mistura de componentes OIB com manto depletado. Isto pode ser possível se a pluma (fonte de OIB), durante sua ascensão, incorpora porções de material mantélico depletado de fonte rasa. Entretanto, apenas os diagramas das figuras 7 e 8 são insuficientes para identificar e caracterizar reservatórios mantélicos, mas são significativos e convincentes se houver complementação com dados isotópicos $(\mathrm{Sr}, \mathrm{Nd} \mathrm{e} \mathrm{Pb})$.

CONCLUSÕES Neste trabalho foram apresentados os primeiros dados geoquímicos para as rochas metavulcânicas máficas do greenstone belt de Riacho de Santana, Estado da Bahia e discutido seu significado petrogenético. O padrão geoquímico (elementos maiores, traços e terras raras) apresentado para essas rochas é semelhante a rochas metavulcânicas de outros greenstone belts do mundo (e.g., Província Superior do Canadá, Províncias Báltica e Yilgarn e Bastar, na Índia).

As rochas meta-vulcânicas máficas da Unidade Intermediária do GBRS podem ser classificadas como toleítos enriquecidos em ferro. As variações de ele- mentos traços com $\mathrm{MgO}$, em particular com $\mathrm{Ni}$ e $\mathrm{Sc}$, sugerem que a cristalização de olivina e clinopiroxênio foram fases minerais importantes no fracionamento magmático. $\mathrm{O}$ comportamento do $\mathrm{Al}_{2} \mathrm{O}_{3}$ com o $\mathrm{MgO}$ é sugestivo do trend de fracionamento do plagioclásio, no entanto, a ausência de anomalia negativa de $\mathrm{Eu}$ depõem contra esta afirmação. A presença de anomalia negativa de $\mathrm{Sr}$ nas rochas meta-vulcânicas do GBRS é semelhante às apresentadas para o embasamento gnáissico-migmatítico arqueano do Bloco do Gavião sugerindo a assimilação/contaminação de componentes crustais na geração destas rochas. Padrões relativamente planos dos ETR pesados e baixas razões de ETRleves/ETRpesados indicam que a fusão mantélica ocorreu em profundidades relativamente rasas, na ausência de granada na fonte.

E, finalmente, os padrões de ETR normalizados para o manto primitivo e as razões de elementos traços sugerem que o magma primitivo das rochas metavulcânicas foi derivado de um reservatório mantélico enriquecido ou uma mistura entre reservatórios enriquecidos e empobrecidos. Razões entre elementos HFS também sugerem a presença de componentes do tipo OIB neste magma. A composição do magma foi significantemente afetada pela assimilação de material crustal, seja pela presença de sedimentos crustais subductados e/ ou afetado por litosfera subcontinental arqueana pouco espessa na região fonte. Trabalhos futuros da composição isotópica destas rochas metavulcânicas poderão auxiliar na avaliação de heterogeneidades mantélicas e confirmar as inferências traçadas sobre a evolução petrogenética e a atuação de processos de assimilação/ contaminação crustal na geração e evolução das rochas meta-vulcânicas máficas do GBRS.

Agradecimentos Os autores agradecem a Coordenação de Aperfeiçoamento de Pessoal de Nível SuperiorCAPES (Processo no 3357/05-8) e a Companhia Baiana de Pesquisa Mineral (CBPM) pelo apoio logístico. Os autores agradecem as sugestões dos revisores deste trabalho.

\section{Referências}

Arndt N.T. 1994. Archean komatiites. In: Condie K.C. (ed.) Archean Crustal Evolution. Elsevier, p. 11-44.

Baksi A.K. 2001. Search for a deep mantle component in mafic lava using a $\mathrm{Nb}-\mathrm{Y}-\mathrm{Zr}$ plot. Can. J. Earth Sci., 38:813-824.

Barbosa J.S.F. \& Dominguez J.M.L. 1996. Texto Explicativo para o Mapa Geológico do Estado da Bahia ao Milionésimo. Salvador, Bahia, SICM/SGM, 400p.

Barbosa J.S.F. \& Sabaté, P. 2002. Geological features and the Paleoproterozoic collision of four Archean crustal segments of the São Francisco Craton, Bahia, Brazil. A synthesis. Anais da Academia Brasileira de Ciências, 75(2):343-359.

Barbosa J.S.F. \& Sabaté P. 2004. Archean and Paleoprotero- zoic crust of the São Francisco Craton, Bahia, Brazil: Geodynamic Features. Precambrian Res., 133:1-27.

Bastos Leal L.R., Teixeira W., Cunha J.C., Macambira M.J.B. 1998. Archean tonalitic-trondhjemitic and granitic plutonism in the Gavião block, São Francisco craton, Bahia, Brazil: geochemical and geochronological characteristics. Rev. Bras.Geoc., 28(2):209-220.

Bastos Leal L.R., Cunha J.C., Cordani U.G., Teixeira W., Nutman A.P., Menezes Leal A.B., Macambira M.J.B. 2003. SHRIMP U-Pb, 207Pb/206Pb zircon dating, and $\mathrm{Nd}$ isotopic signature of the Umburanas greenstone belt, northern São Francisco craton, Brazil. J. South American Earth Sci., 15:775-785.

Bateman R., Costa S., Swe T., Lambert D. 2001. Archaean 
mafic magmatism in the Kalgoorlie area of the Yilgarn Craton, Western Australia: a geochemical and Nd isotopic study of the petrogenetic and tectonic evolution of a greenstone belt. Precambrian Res., 108:75-112.

Benn K., Mareschal J.-C., Condie K.C. 2006. Introduction: archaean geodynamics and environments. In: Benn K., Mareschal J.-C., Condie K.C. (eds.) Archean Geodynamics and Environments. AGU Geophys. Monograph Series, 164:1-5.

Beresford S.W., Cas R.A.F., Lahaye Y., Jane M. 2002. Facies architecture of an Archean komatiite-hosted Ni-sulphide ore deposit, Victor, Kambalda, Western Australia: implications for komatiite lava emplacement. J. Volcanology and Geothermal Research, 118:57-75.

Brewer T.S., Menuge J.F. 1998. Metamorphic overprinting of Sm-Nd isotopic systems in volcanic rocks: the Telemark Supergroup, southern Norway. Chem. Geol., 145:1-16.

Campbell I.H. 1985. The difference between oceanic and continental tholeiites: a fluid dynamic explanation. Contrib. Miner. Petrol., 91:37-43.

Chavagnac V. 2004. A geochemical and Nd isotopic study of Barberton komatiites (South Africa): implication for the Archean mantle. Lithos, 75:253-281.

Chen C-Y \& Frey F.A. 1983. Trace element and isotopic geochemistry of lavas from Haleakala Volcano, East Maui, Hawaii: implications for the origin of Hawaiian basalts. J. Geophy. Research, 90:8743-8768.

Chen C-Y \& Frey F.A. 1985. Origin of Hawaiian tholeiiteand alkalic basalt. Nature 302:785-789.

Condie K.C. (ed.) 1994. Archaean Crustal Evolution. Amsterdam, Elsevier, p. 528.

Condie K.C. 1981. Archean Greenstone Belts. Amsterdam, Elsevier, 435p.

Condie K.C. 2003. Incompatible element ratios in oceanic basalts and komatiites: tracking deep mantle sources and continental growth rates with time. Geochem. Geophys. Geosyst., 4(1):1005, doi:10.1029/2002GC000333.

Condie K.C. 2005. High field strength ratios in Archean basalts: a window to envolving sources mantle plumes? Lithos, 79:491-504.

Cousens B., Facey K., Falck H. 2002. Geochemistry of the late Archean Banting Group, Yellowknife greenstone belt, Slave Province, Canada: simultaneous melting of the upper mantle and juvenile mafic crust. Can. J. Earth Sci., 39:1635-1656.

Cox K.G. \& Hawkesworth C.J. 1985. Geochemical stratigraphy of the Deccan traps at Mahabaleshwar Western Ghats, India with implication for open system magmatic processes. J. Petrol., 26:355-377.

Cunha J.C. \& Fróes R.J.B. 1994. Komati1tos com textura spinifex do Greenstone belt de Umburanas, Bahia. Salvador, Série Arquivos Abertos, Companhia Baiana de Pesquisa Mineral-CBPM, 29p.

de Wit M.J. 1998. On Archean granites, greenstones, cratons, and tectonics: does the evidence demand a verdict? Precambrian Res., 91:181-226.

Dostal J. \& Mueller W. 1997. Komatiite flooding of a rifted Archean rhyolite complex: geochemical signature and tectonic significance of the Stoughton-Roquemaure Group, Abitibi greenstone belt, Canada. J. Geol.,
105:545-563.

Dostal J. \& Mueller W.U. 2004. Komatiite geochemistry. In: Eriksson P.G., Altermann W., Nelson D.R., Mueller W.U., Catuneanu O. (eds.) The Precambrian Earth: Tempos and Events. Amsterdam, Elsevier, p. 290-298.

Fitton J.G., Saunders A.D., Norry M.J., Hardarson B.S., Taylor R.N. 1997. Thermal and chemical structure of the Iceland plume. Earth Planet. Sci. Lett., 153:197-208.

Galer S.J.G. \& O’Nions R.K. 1985. Residence time of thorium, uranium, and lead in the mantle with implications for mantle convection. Nature, 316:778-782.

Hart S.R., Hauri E.H., Oschmann L.A., Whitehead J.A. 1992. Mantle plumes and entrainment: isotopic evidence. Science, 256:517-519.

Hofmann A.W., White W.M. 1983. Ba, Rb and Cs in the Earth's mantle. Zeitschift fur Naturforschung, 38a:256266.

Humphris S.E. \& Thompson G. 1978. Trace element mobility during hydrothermal alteration of oceanic basalts. Geochim.Cosmochim. Acta, 42:127-136.

Irvine T.N. \& Baragar W.R.A. 1971. A guide to the chemical classification of the common volcanic rocks. Can. J. Earth Sci, 8:523-545.

Jensen L.S. 1976. A new cation plot for classifying sub-alkaline volcanic rocks. Ontario division Mines Miscellaneous, Paper No. 66, 22p.

Kerrich R. \& Fryer B.J. 1979. Archean precious metal hydrothermal systems Dome Mine Abitibit greenstone belt; II REE and oxygen isotope relations. Can. J. Earth Sci., 16:440-458.

Kusky T.M. \& Polat A. 1999. Growth of granite-greenstone terranes at convergent margins, and stabilization of Archean cratons. Tectonophysics, 305:43-73.

Ludden J., Gelienas L., Trudel P. 1982. Archean metavolcanics from the Rouyn-Noranda district, Abitibi greenstone belt, Quebec: 2. Mobility of trace elements and petrogenetic constraints. Can. J. Earth Sci., 19:2276-2287.

Mahoney J.J., Macdougall J.D., Lugmair G.W., Gopalan K. 1983. Kerguelen hotspot source for Rajmahal Traps and Ninetyeast Ridge? Nature (London), 303:385-389.

Manikyamba C., Kerrich R., Naqvi S.M., Mohan M.R. 2004. Geochemical systematics of tholeiitic basalts from the 2.7 Ga Ramagiri-Hungund composite greenstone belt, Dharwar craton. Precambrian Res., 134:21-39.

Manikyamba C., Naqvi S.M., Rao D.V.S., Mohan M.R., Khanna T.C., Rao T.G., Reddy G.L.N. 2005. Boninites from the Neoarchean Gadwal Greenstone belt, Eastern Dharwar Craton, India: implications for Archean subduction processes. Earth Planet. Sci. Lett., 230:65-83.

Marinho M.M. 1991. La Sequence Volcano-Sedimentaire de Contendas-Mirante et la Bordure Ocidentale du Bloc de Jequié (Craton du São Francisco, Brésil): un example de transition archeen-proterozoique. Unpublished $\mathrm{PhD}$ Thesis, University of Clermont-Ferrand, France, 388p.

Marinho M.M., Galvão C.F., Nonato I.F., Brito R.S.C. 1994. Geologia e potencialidade mineral da borda nordeste da Faixa Contendas-Mirante e do Sill do Rio Jacaré. Salvador: Companhia Baiana de Pesquisa Mineral - CBPM, Série Arquivos Abertos, v.6, 17p.

McDonough W.F., Sun S.S., Ringwood A.E., Jagoutz E. 
1987. Rb and Cs in the Earth and Moon. In:Lunar and Planetary Science Conference, Abstract, 18:610-611.

McDonough, W.F. \& Sun S.S. 1995. The composition of the Earth. Chem. Geol., 120:223-253.

Menezes Leal A.B. \& Paul D. 2006. Geochemistry and origin of the tholeiitic mafic metavolcanic rocks from the Riacho de Santana greenstone belt, Bahia, Brazil. In: GSA Annual Meeting, 2006, Pensilvânia, Filadelfia, Geological Society of America Abstracts, 38(7):493.

Menezes Leal A.B., Paul D., Cunha J.C. 2007. Geochemistry of contaminated Komatiites from the Umburanas greenstone belt, Bahia State, Brazil. In: GSA Annual Meeting, Denver, Colorado, Geological Society of America Abstracts, 39(6):222.

Mohr P.A. 1987. Crustal contamination in mafic sheets: a summary. In: Halls H. \& Fahrig W.F. (eds.) Mafic Dyke Swarms. Geological Association of Canada Special Paper, 34:75-80.

Murphy J.B., Hynes A.J. 1986. Contrasting secondary mobility of Ti, P, Zr, Nb, and Y in two metabasaltic suites in the Appalachians. Can. J. Earth Sci., 23:1138-1144.

Parman S.W., Grove T.L., Dann J.C. 2001. The production of Barberton komatiites in an Archean subduction zone. Geophys. Res. Lett., 28:2513-2516.

Parman S.W., Shimizu N., Grove T.L., Dann J.C. 2003. Constraints on the pre-metamorphic trace element composition of Barberton Komatiites from ion probe analyses of preserved clinopyroxene. Contrib. Mineral. Petrol., 144:383-396.

Peucat J.J., Mascarenhas J.F., Barbosa J.S.F., Souza S.L. de, Marinho M.M., Fanning C.M., Leite C.M.M. 2002. 3.3 Ga SHRIMP U-Pb zircon age of a felsic metavolcanic rock from the Mundo Novo greenstone belt in the São Francisco craton, Bahia (NE Brazil). J. South American Earth Sci., 15:363-373.

Polat A. \& Kerrich R. 2001. Magnesian andesites, Nb-enriched basaltandesites, and adakites from late Archean 2.7 Ga Wawa greenstone belts, Superior Province, Canada: implications for late Archean subduction zone petrogenetic processes. Contrib. Mineral. Petrol., 141:36-52.

Polat A. \& Hofmann A.W. 2003. Alteration and geochemical patterns in the 3.7-3.8Ga Isua greenstone belt, West Greenland. Precambrian Res., 126:197-218.

Polat A. \& Kerrich R. 2006. Reading the geochemical fingerprints of Archaean hot subduction volcanic rocks: evidence for accretion and crustal recycling in a mobile tectonic regime. In: Benn K., Mareschal J.-C., Condie K.C. (eds.) Archean Geodynamics and Environments. AGU Geophys. Monograph Series, 164:189-213.

Polat A., Kerrich R., Wyman D.A. 1998. The late Archean Schreiber-Hemlo and White River-Dayohessarah greenstone belts, Superior Province: collages of oceanic plateaus, oceanic island arcs, and subduction-accretion complexes. Tectonophysics, 289:295-326.

Polat A., Kerrich R., Wyman D.A. 1999. Geochemical diversity in oceanic komatiites and basalts from the late Archean Wawa greenstone belt, Superior Province, Canada: trace element and $\mathrm{Nd}$ isotope evidence for a hetero- geneous mantle. Precambrian Res., 94:139-173.

Puchtel I.S., Hofmann A.W., Amelin Y.W., Grabe-Schonberg C.-D., Samsonov A.V., Shchipansky A.A. 1999. Sumozero-Kenozero greenstone belt, SE Baltic Shield: isotope and trace element constraints. Geochim. Cosmochim. Acta, 63:3579-3595.

Rollinson H. 1993. Using Geochemical Data: Evolution, Presentation, Interpretation. UK, Longman Scientific and Technical, p. 344.

Schilling J.G., Thompson G., Kingsley R., Humphris S. 1985. Hotspot-migrating ridge interaction in the South Atlantic. Nature, 313:187-191.

Silva M.G. 1983. A Sequencia Vulcanossedimentar do Medio Rio Itapicuru (Ba): Caracterização Petrográfica, Considerações Petrogenéticas Preliminares e Zoneografia Metamorfic. Dissertação Mestrado, IGEO/UFBA, 120p.

Silva M.G. 1987. Petrologie, Geochimie und tektonische Entwickulung eines proterozoischen Gruensteinguertels, Rio Itapicuru Bahia, Brasilien. Albert-Ludwigs Universität Freiburg, ALUF, Alemanha, 168p.

Silva M.G. 1994. Greenstone Belt do Rio Itapicuru: Uma Bacia do Tipo Back Arc Fóssil. Rev. Bras. Geoc., 22(2):157166.

Silveira W.P., Fróes J.R.B., Bastos Leal L.R. 1996. Geologia e potencial metalogenético do greenstone belt de Riacho de Santana. In: Congresso Brasileiro de Geologia, 39, Salvador, 1:109-112.

Silveira W.P. \& Garrido I.A.A. 2000. Geologia, Pesquisa Mineral e Potencialidade Econômica do Greenstone Belt Riacho de Santana. S.A.Abertos, CBPM, 14, 39p.

Smithies R.H., Champion D.C., van Kranendonk M.J., Howard H.M., Hickman A.H. 2005a. Modern-style subduction processes in the Mesoarchean: geochemical evidence from the 3.12Ga Whundo intraoceanic arc. Earth Planet. Sci. Lett., 231:221-237.

Smithies R.H., Van Kranendonk M.J., Champion D.C., 2005 b. It started with a plume-early Archean proto continental crust. Earth Planet. Sci. Lett., 238:284-297.

Srivastava R.K., Singh R.K., Verma S.P. 2004. Neoarchaean mafic volcanic rocks from the southern Bastar greenstone belt, Central India: petrological and tectonic significance. Precambrian Res., 131:305-322.

Sun S.-S. \& McDonough W.F. 1989. Chemical and isotopic systematic of oceanic basalts: implications for mantle composition and processes. In: Saunders A.D. \& Norry M.J. (eds.) Magmatism in the Ocean Basins. Geol. Soc. Lond. Spec. Publ, 42:313-345.

van Kranendonk M.J. 2004. Archean tectonics, a review. Precambrian Res., 131:143-151.

Weaver B.L. 1991. The origin of ocean island basalt endmember compositions: trace element and isotopic constraints. Earth Planet. Sci. Lett., 104:381-397.

Manuscrito ID 8559 Submetido em 09 de agosto de 2007 Aceito em 20 de setembro de 2008 Sistema eletrônico de submissão 